\title{
Trust and Organizational Resilience in the Nigerian Oil and Gas Industry
}

\author{
S. O. Olu-Daniels ${ }^{1} \&$ B. M. Nwibere ${ }^{1}$ \\ ${ }^{1}$ University of Port Harcourt, Nigeria \\ Correspondence: B. M. Nwibere, University of Port Harcourt, Nigeria. E-mail: barrysaro@yahoo.com
}

Received: November 12, 2013

Accepted: December 18, 2013 Online Published: January 26, 2014

doi:10.5539/ijbm.v9n2p291

URL: http://dx.doi.org/10.5539/ijbm.v9n2p291

\begin{abstract}
The study examined the relationship between trust and organizational resilience. The sample for the study consisted of two hundred and ten (210) randomly selected managers from thirty seven (37) companies in the upstream sector of the oil and gas industry in South-South geopolitical region of Nigeria. The study adopted a triangulation of methodology (utilized both quantitative data from questionnaire and qualitative data from interviews). The Spearman Rank Order Correlation Coefficient and Multiple Regression Model using the Statistical Package for Social Sciences (SPSS) version 17 were utilized for the analysis of data. Our findings revealed a positive and significant relationship between trust and organizational resilience within the upstream sector of the oil and gas industry in the South-South region of Nigeria. More specifically, all the dimensions of trust (competence, openness, and reliability) were revealed to have positive and significant relationships with the measures of organizational resilience (vulnerability and adaptive capacity). Based on the findings above, it was concluded that trust (competence, openness, and reliability) enhances organizational resilience (vulnerability and adaptive capacity). The managerial implications of these findings were also discussed.
\end{abstract}

Keywords: trust, organizational resilience, oil and gas industry, south-south region, Nigeria

\section{Context of the Problem}

We are living in times of great uncertainties. There are various daunting issues confronting the society, individuals and entrepreneurs alike, of which being proactive and making the right decisions or taking appropriate courses of actions could be the only saving grace. Globally and in Nigeria to be specific, reforms are being introduced daily and there are indications of suspicions all around. There is no guarantee that the infrastructural facilities of today will be available tomorrow. In the world we live in today, the patterns of market disruption and accelerated change have become the norm, rather than the exception. To compound these issues, there are unrests and clamours by various segments of the society which could sometimes be devastating with far reaching effects on the society, business inclusive. To this end, there have been calls for revolution to cleanse the society (Agbaje, 2010). To compound issues, there is suspicion among the various ethnic nationalities within the Nigerian nation leading to widespread calls for self determination and in some cases, violent demonstrations and militancy. Whether a revolution will take place or whether a bomb will be detonated or whether there will be violent demonstrations or whether none of this will happen is anybody's guess. But one thing that is apparent and certain, is that the potentials are there for any of these to occur with devastating consequences.

As our society becomes increasingly complex and interdependent we are becoming more vulnerable to disruptive events from a broad range of threats and hazards. These disruptive events, if not properly managed, can escalate into emergencies, crisis, or even disasters. When disruptive events occur, they have telling effects on the society as a whole, business organizations inclusive. It can taint an organization's image, reputation or brand, in addition to resulting in significant physical or environmental damage, injury or loss of life; given that we operate in immensely complex environments with numerous threats (Sutcliffe, 2010). These are the realities of our times. Nigeria is not immuned from these realities as we are in a global world.

With these realities and the associated telling effects, it is imperative that appropriate steps be taken and plans put in place to protect the going concern craving of organizations. As Hamel (2007) rightly observed, "organizations confront increasing complexity in globalizing markets and are constantly challenged to learn and change in a way for which they have no precedent". In the business community, corporate threats are increasing daily. In an earlier study by Serrano (2009) it was revealed that between 1994 and 2003, 50 percent of the largest global companies 
suffered declines in share price value of more than 20 percent in a single one-month period. Up to half of this group took two years or more to recover to the share price level before the drop occurred. This is evidence of the fact that organizations deal with uncertainties and unexpected events all the time, and that the way and manner these uncertainties and unexpected events are managed presents both opportunities and risks for the organizations. Seville (2011) succinctly puts it this way, "being able to respond effectively to crisis events is a real test of what makes an organization 'tick"". This is the essence of organizational resilience as the definition above succinctly captures its meaning.

Sutcliffe, (2010) argue that even with the best of intentions, managers often have little time and energy to plan for adversity; and even when they do enact sophisticated risk management strategies, they are often unable to predict the challenges that may arise. In the light of this, they need to shift from implementing contingency plans to building organizations that are flexible, learn, grow, and come back stronger when faced with adversity. Organizations that have harnessed this capacity to bounce back can be termed "resilient". Resilience, while often used to describe individuals who have overcome hardship, has increasingly been used to refer to organizations as well. The adverse economic implications of organizations being unprepared for uncertainties and disruptive events are significant as the September $11^{\text {th }}$ attacks showed. It is obvious that when such disruptive events occur, losses from business interruption far exceeded the sum of all property losses. In our increasingly interconnected and interdependent business environment, consequences go well beyond the zone of any physical damage, affecting businesses right along the supply chain. That is why the term 'resilience' is coming into prominence within business and management circles today. This may explain why according to Serrano (2009), corporate and community leaders are increasingly understanding the relevance of a concept that encompasses both the technological and systemic, as well as the human and cultural factors, that help organizations and communities thrive in an era of uncertainty, ever-increasing change, competitive pressures, and exogenous threats. Closely allied to the above, Ceridian (2011) argued that a resilient organization can respond and adapt to both sudden shocks and gradual change - the current financial crisis is a perfect test of resiliency. Maximizing performance over the long term, through changes foreseen and disruptions that can't be predicted, defines a resilient organization.

All these point to the fact that resilience is an important element that forward looking organizations cannot afford to ignore. It had previously been thought that all an organization requires to thrive and survive is to place emphasis on efficiency in the production process. In fact, it was argued then that the idealised conceptualization of a business is one in which there is "maximum production at zero cost" if this was possible. The reality is that today, this notion is no longer acceptable. Business success and survival today is to a large extent dependent on how resilient organizations are. To buttress this point, Feather (2011) argued that "trees survive terrible storms if they can bend in the wind. Species who cannot adapt to new conditions die out and get buried. The natural world's proclivity toward flexibility is also rewarded in humans". Eventually, resilient individuals can achieve success, sometimes after hundreds of attempts at their dream. At its core, resilience is the spark of determination that empowers us to get up and try again, no matter what the circumstances. We have seen time and again that the most successful businesses are resilient enough to bounce back from any crisis. The old model of an "input-output," industry-specific path to success has begun to rapidly give way to a new model of dynamic connections between diverse industry groupings (i.e. computers-telecommunications-entertainment-financial institutions) that operate in a full 360 degree sphere of competitive possibilities. Zuboff (1988) presaged this shift when she stated that "... we believe that a machine-oriented point of view has reached the limits of its ability to help workers perform their jobs. To this point, an inadequate amount of attention has been paid to the knowledge worker.... We have ended up with organizations whose workers are systems users, not knowledge workers or system-enabled service workers".

The challenges that businesses face today are not questions that relate to degrees of success. They concern a far more critical issue - survival. The time-consuming, efficiency-refining processes that have been the mainstay of organizational focus for so long no longer have the competitive breathing room to work their magic. Horne (1997) argues that there are several questions that the leaders of the organization need to address: "How does an organization shift from a centuries-old, entrenched, machine metaphor model of operation to one that reflects a more fluid structure that is better able to address issues of rapid and often unpredictable change? What is the proper metaphor-model to use as the visioning springboard for creating the new organization?" These and many more are pertinent questions that are begging for answers and yet remain unattended.

In an investigation of the factors explaining the success of some airline companies after the September, 2001 attacks and the struggles of others, the findings of Gittell et al. (2005) revealed that two key factors can account for organizational resilience, namely, the existence of relational reserves (the maintenance of positive employee 
relationships) and financial reserves. These two building blocks in combination are the key predictors of organizational resilience. This paper however seeks to ascertain whether or not relational reserves can be engendered by mutual trust. On his part, Fukuyama (1995) argues that globalization, workplace diversity, increased awareness of cultural differences, downsizing, delayering, the call for (and in some cases the reality of) increased workplace democracy, international networks, complex alliances, information technologies, and decentralized decision making are only some of the events and processes during which trust assumes significant importance. Fukuyama (1995) went further to state that trust within and across organizations is conceived by many to be directly related to the ability to form new associations and networks of trusting relationships to accomplish business transactions and, therefore, is predictive of whether or not an organization will remain viable. In a time of increased imperatives for change and less certainty about how change can and should occur, it is not surprising that a renewed interest in trust surfaces as scholars and practitioners alike seek to understand relationships among trust, cooperative behaviors, and organizational abilities to change and build resilience (Kramer \& Tyler, 1996). A general consensus among researchers has emphasised the place of trust in a range of organizational activities and processes such as team work, leadership, goal setting, performance appraisal, and in general, cooperative behaviors (Bhattacharya et al., 1998; Butler, 1991; Gittell et al., 2005; Hosmer, 1995; Mayer et al, 1995; Shockley-Zalabak et al., 2011a). Specific studies in the relationship of trust with organizational resilience are however, sparse.

From the discussions above, it is obvious that there have been several studies on the concepts of trust and organizational resilience. This is particularly so as the matters of building a resilient organization through the development of trusting relationships and systems are expedient for a going concern in a world where change and continuous adaptation have become imperatives for success and survival. However, what is less clear is how successful firms have been in utilising these systems in encouraging and developing resilience in their ranks (Feather, 2011; Claudio-Pascua, 2011; Ouchi, 1981). This study therefore, strives to bridge this gap in the management literature by examining the relationship between trust and organizational resilience. It would be interesting to evaluate how trust in an organization impacts on the building of resilience in the Nigerian environment and the upstream sector of the oil and gas industry to be specific. In addition, this study will seek to evaluate the moderating effects of structure and culture of an organization on the relationship between trust and organizational resilience.

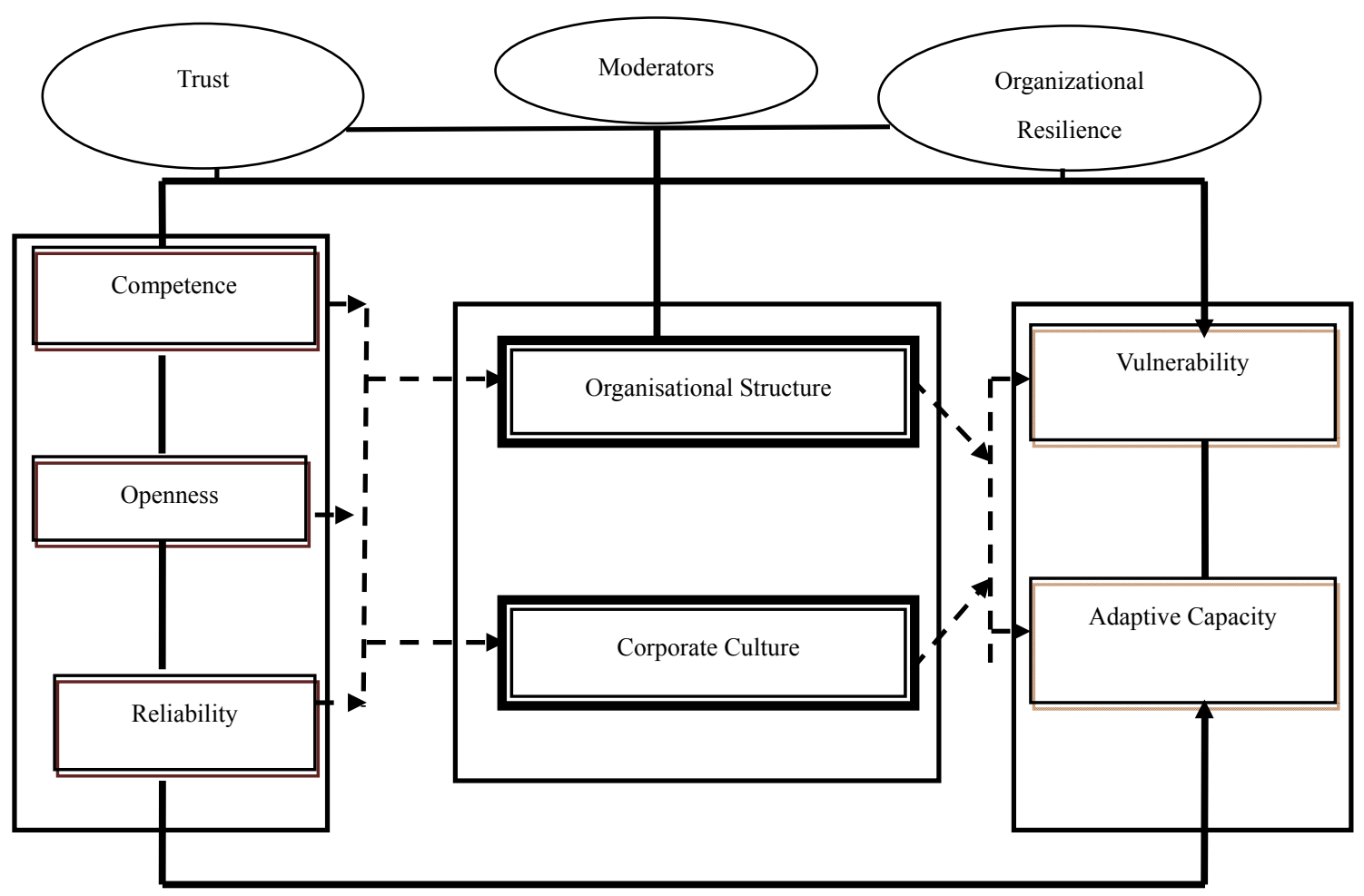

Figure 1. Framework for analyzing the relationship between trust and organizational resilience

Source: Conceptualised by the Researchers 


\section{Review of Related Literature}

The need to re-shape for competitive edge was ever present. According to Thurow (1996), there have been major shifts in the dynamic forces that underlie the economic world. Thurow (1996) noted that knowledge has become the only source of sustainable competitive advantage, but knowledge can only be employed through the skills of individuals, and as with everything else, knowledge and skills will move around the world. The issues that businesses face today are not questions that relate to degrees of success. They concern a far more critical issue survival. As we enter deep into the $21^{\text {st }}$ century, the economy of much of the industrialized world is moving at an accelerating pace toward an information-based structure. According to Horne (1997), the essence of much production, centres on "transactions", not "products". A shift from an emphasis on efficient control/predictability to an effectiveness orientation, which may include creative, flexible, and unpredictable elements in the process, is necessary for continued gain. The most flexible and creative element in the organization should be the work force itself.

It is this realisation that has now led to greater interests in organizational resilience, with its quantum reaction with an organization's desire for survival and growth. The interest is now not so much on productivity and performance, which are no doubt important measures in an organization's existential capacity, but on how adaptable the organization is as measured by its resilience. Without placing premium on resilience, performance cannot be sustained (Aston, 2011). This underscores the role of organizational resilience in the management of today.

Gittell et al (2005) posited that the terrorist attacks of September 11th, 2001 affected the U.S. airline industry more than almost any other industry. In addition to the devastating loss of employees' lives, passenger ridership plummeted and financial losses were horrendous. Certain of these companies emerged successful, however, and demonstrated remarkable resilience while others languished. They went further to propound reasons why some airline companies recovered successfully after the attacks while others struggled. They concluded that the difference was in the resilience of the organizations.

Organizational resilience is seen as the ability of a material or system to absorb change gracefully whilst retaining core properties or functions (Seville, 2011). In Serrano's (2009) view, organizational resilience is a concept that encompasses both the "technological and systemic, as well as the human and cultural factors, that help organizations and communities thrive in an era of uncertainty, ever-increasing change, competitive pressures, and exogenous threats".

Seville (2011) succinctly summarised the various approaches to defining organizational resilience when he identified: "three key aspects of organizational resilience: vulnerability, adaptive capacity and awareness". This is schematically presented in Figure 2.1 below. Resilience is about ensuring that an organization is still able to achieve its core objectives in the face of adversity. This means not only reducing the size and frequency of crises (vulnerability), but also improving the ability and speed of the organization to manage crises effectively (adaptive capacity). Awareness is a recent addition to this definition and reflects a growing appreciation of the need to manage strategic risks as a process and not an event. This means the ability of the organization to seek out new opportunities even in times of crisis.

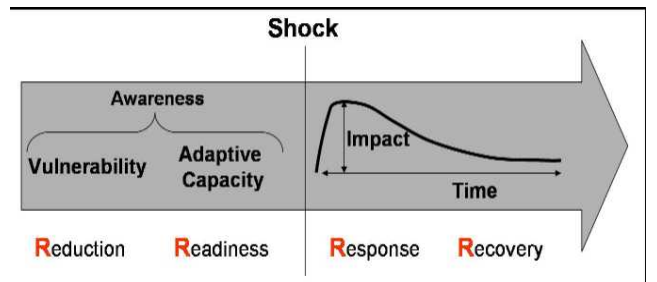

Figure 2. Key aspects of organizational resilience

In highly dynamic environments, such as the business world, an organization is never a static entity. Some sectors will be more stable than others, but nevertheless, an organization that remains exactly the same over time will eventually erode its potential. This means that to be truly resilient, an organization should not seek to just recover back to exactly where it was before the crisis, but have the reserves to continue looking for emerging risks and opportunities on the horizon. Severity and duration of impact on performance is a measure of an organization's resilience, where resilience is inversely proportional to the area under the curve (see Figure 2 above). An 
organization is most resilient when it is able to scan new circumstances with curiosity, not knowing in advance what it will do, but confident that it will interact in ways that lead to things working well".

Some of the characteristics of a resilient organization include having connections (horizontal and vertical linkages), optimism, unity, effective communication, survivor instincts, interdependency, understanding, cohesion, ability to bounce back, shared vision, innovation, self reliance and flexibility. To build an organization that is resilient requires communication, coordination of efforts, development of competences, consideration by organizational leadership, encouraging innovation, building in flexibility, strengthening and broadening connection networks, building a sense of purpose and managing employee stress (Ceridian, 2011).

The measures of organizational resilience of concern in this study are vulnerability and adaptive capacity. Vulnerability is generally described as the human product of any physical exposure to a disaster that results in some degree of loss, combined with the human capacity to withstand, prepare for and recover from that same event while adaptive capacity is "the extent to which a system can modify its circumstances to move to a less vulnerable condition" (Luers et al, 2003).

The place of trust in the organization was extolled by Mullins, (2005) when he posited that forces of global competition and turbulent change make employment guarantees unfeasible and demand a new management philosophy based on trust and teamwork. To be effective as an organization, it is imperative that a trust culture be promoted. Lack of trust is probably one of the greatest time and resource wasters in the workplace. Trust within and across organizations is conceived by many to be directly related to the ability to form new associations and networks of trusting relationships to accomplish business transactions and, therefore, is predictive of whether or not an organization will remain viable (Fukuyama, 1995).

Many researchers have put forward a number of definitions which can be captured in Mayer et al's (1995) definition. They described trust as "the willingness of a party to be vulnerable to the actions of another party based on the expectation that the other party will perform a particular action important to the trustor, irrespective of the ability to monitor or control the other party". The various definitions reflect three basic facets of trust: (a) trust in another party reflects an expectation or belief that the other party will act benevolently; (b) a party cannot control or force another party to fulfill the expectation - that is, trust involves a willingness to be vulnerable and to assume risk; and (c) trust involves some level of dependency on the other party so that the outcomes of one party are influenced by the actions of another (Shockley-Zabalak, et al., 2011).

Developing a setting of trust in an organization demands concerted effort on the part of all organization members. The six perspectives of the Organizational Trust Index can help managers evaluate the level of trust in their organization, determine the degree to which their culture is either motivated by trust or driven by fear, and provide a step-by-step process for building a culture that is based on trust. The Organizational Trust Index, according to Bodnarczuk's (2008) review consists of six perspectives: Truth, Integrity, Power, Competency, Values, and Recognition. However, this study adopted Mishra's (1996) model with dimensions being competence, openness and reliability. The other two dimensions of concern and identification have been subsumed in openness because according to Cummings and Bromiley (1996), when an organization is open in its dealings with organizational members, concern and identification fall into place. This position was corroborated by Ellis and Shockley-Zalabak (1999) when they posited that identification and concern highlight that trust is inherently the result of communication behaviors and interpretative processes. As was noted earlier, openness thrives on communication. Future researches may however, isolate these two dimensions for further in-depth studies.

It has been said that organizational resilience is an important attribute that forward looking organizations covet at these turbulent times when potentials for devastating situations and events are probable. It has also been noted that to achieve resilience, an organization will need the total and effective contributions of all its members. To obtain this participation and contribution from members of the organization, it demands that the members believe in the cause and see the benefits accruable to them. As Gittelle et al. (2005) propounded, the role of relationships is especially important when considering how individuals and organizations respond to crises. Most organizational theory has focused on the negative consequences of crisis such as threat-rigidity, downward spirals, vicious cycles, and tipping points (Gittell et al, 2005; Weick, 1996), yet some organizations demonstrate a remarkable tendency to flourish and thrive in the midst of crisis. These organizations demonstrate resilience traceable to relationships and trust in the relationships.

This study aims to study the impact of trust on organizational resilience. The literature reviewed thus far has shown that the organization's resilience is enhanced by the subsistence of a trust setting. It has also been discovered that the structure and culture of the organization, that empower the employees and support the employees in realizing their personal goals within the organization, influence the achievement of a resilient 
organization (Bass, 1992; Mullins, 2005; Dalziell \& McManus, 2011; Longstaff \& Yang, 2008). Against this backdrop, this study further examines the role of structure and culture of the organization in moderating the relationship between trust and organizational resilience.

Structure is an organizational action that reflects the extent to which the leader defines and organizes group interactions towards attainment of formal goals and organises group activities. This dimension is associated with efforts to achieve both individual needs and organizational goals (Mullins, 2005). A popular and simple way of defining culture is: "how things are done around here" (Mullins, 2005). A more detailed definition was given by McLean and Marshall (1993). They defined culture as "the collection of traditions, values, policies, beliefs, and attitudes that constitute a pervasive context for everything we do and think in an organization".

\section{Research Metholodolgy}

\subsection{Sampling Procedure}

The sample for the study consisted of two hundred and ten (210) randomly selected managers from the selected upstream oil and gas companies in South-South region of Nigeria. The sample was restricted to the managers in these companies in view of the responses required in the study, which can only be meaningfully provided by the top echelon of the organizations, particularly as they relate to the resilience of the organizations. The unit of analysis was at the organizational level. The procedure involved a determination of the relevant companies from the list of upstream companies obtained from the Port Harcourt office of the Department of Petroleum Resources (DPR), which is an arm of the Nigerian National Petroleum Corporation of Nigeria (NNPC). The companies that qualified for inclusion were those who qualify as an upstream company and having presence in the South-South zone. It was observed that some of the marginal field concessionaires were yet to have any meaningful presence in the South-south region of Nigeria. Additional information on the relevant companies was also obtained from various websites on the internet (Mbendi, 2011; Uche, 2011; Bright, 2011; NNPC, 2010a; NNPC, 2010b; NNPC, 2010c). The searches revealed a total of 37 qualified companies listed in Appendix A. All the companies were sampled.

The choice of respondents from each company was determined through cluster sampling with each company representing a "cluster". To assure a choice that is evenly spread among the companies, selection from the clusters to arrive at the desired sample size was by systematic sampling complemented with simple random sampling techniques.

The information obtained from the various companies revealed that there were a total of 457 managers in these companies. The sample size was determined by the application of Taro Yamen's formula suggested by Baridam, (2001) and Freund et al (1979):

$$
n=\frac{N}{1+N(e)^{2}}
$$

Where:

$\mathrm{n}=$ sample size sought

$\mathrm{N}=$ Population size

$\mathrm{e}=$ Level of Significance ( 0.05 desired in this study)

Applying the above formula, a sample size of 213 was obtained. That is, $n=\frac{457}{1+457(0.05)^{2}}=213$

The authors adopted a triangulation of methodology in this study. Firstly, this study utilized quantitative data (questionnaire) or cross sectional survey which has become more appropriate for social/administrative science research as it is perceived to be more anonymous; is also perceived to be budget and time effective and; it allows respondents ample time to think about the questions as well as their responses (Nwibere \& Emecheta, 2012). Secondly, to complement the quantitative data obtained using the survey instrument (questionnaire), the researchers also collected qualitative data using interview. In the course of the study some of the respondents were asked series of unstructured interview questions in an attempt to gain more insights into the issues arising there from.

\subsection{Operational Measures of Variables}

The independent variable in this study is trust. The dimensions of trust were adopted from the earlier study of Mishra (1996) and include: competence, openness, and reliability. Sample items used in operationalising each of these dimensions of trust are indicated in the appendix. The responses to the questions were rated on a 5-point 
Likert-type scale, ranging from 1-5; where 5 was dummy coded "strongly agree" and 1 was dummy coded "strongly disagree". The alpha coefficient for trust was 0.94 .

On the other hand, the dependent variable in this study is organizational resilience. The measures of this variable were adapted from the earlier study of Seville, (2011) and include: vulnerability and adaptive capacity. Sample items used in operationalising each of these measures of organizational resilience are indicated in the appendix. The responses to the questions were rated on a 5-point Likert-type scale, ranging from 1-5; where 5 was dummy coded "strongly agree" and 1 was dummy coded "strongly disagree". The alpha coefficient for organizational resilience was 0.89 .

Furthermore, the moderating effect of two variables (organizational structure and corporate culture) on the relationship between trust and organizational resilience were also examined in this study. Based on the earlier study of Dennison (1990) corporate culture was measured along four major dimensions: Involvement index, Consistency index, Adaptability index, and Mission index. Two questions were used to measure each of these dimensions. Sample items used in operationalising the corporate culture are indicated in the appendix. All items used in operationalising corporate culture were adapted from Dennison (1990) and the response modes were on a 5 -point Likert-type scale ranging 1-5; where 5 was dummy coded "strongly agree" and 1 was dummy coded "strongly disagree".

On the other hand, all items used in operationalising organizational structure were adapted from Hage and Aiken (1967) who had earlier defined organizational structure as practices being undertaken in an organization with regard to policies, procedures, and rules. Two important features of organizational structure as contained in the definition above are formalization and centralization, which according to Hage and Aiken (1967), (and later supported by Hall, 1991 and Matherly, 1985), can further be subdivided into four sub-dimensions: decision-making, hierarchy of authority, job codification, and rule observation. Sample items used in operationalising each of these dimensions of organizational structure are indicated in the appendix. The response modes were on a 5-point Likert-type scale ranging 1-5 where 5 was dummy coded "strongly agree" and 1 was dummy coded "strongly disagree".

It is relevant to note that all instruments used in this study were modified to suit the purpose of this study and our peculiar Nigerian environmental circumstance.

\subsection{Test of Validity and Reliability of Research Instrument}

Several important steps were taken to enhance the validity of the survey instrument utilized in this study. The initial copies of the survey instrument were first given to two Professors in the field of organizational behaviour and management for their scrutiny. The initial copies of the questionnaire were also given to some of our lecturer colleagues for their constructive criticisms and/or suggestions. Their comments and/or suggestions were carefully noted and used to modify the contents of the initial draft of the survey instrument. After the modifications on the initial draft of the survey instrument, a pilot testing was also carried out using 12 workers of the Port Harcourt office of the Shell Petroleum Development Company of Nigeria (SPDC). Their responses led to some modifications in the survey questionnaire contents prior to its administration. To further ensure the validity of the data so collected, a covering letter explaining the objective of the study and assuring the respondents of anonymity and confidentiality of their response was attached to each copy of the survey instrument. The respondents were also promised an electronic copy of the research report (if requested) as an incentive for participating in the survey by the research instrument.

These experts also confirmed that sampling validity was adequately achieved with the organizations that were used for this study.

On the other hand, for our present purpose, the reliability of our survey instrument was tested by means of the "Test-Retest Reliability" method. The test showed a good relationship with a coefficient of reliability of 0.9. Similarly, the reliability analysis in the SPSS environment returned a Cronbach Alpha test value or score of 0.843 .

\subsection{Data Analysis Technique}

Data for this study were analysed by means of the Multiple Regression Model and the Spearman Rank Correlation Coefficient (rho) statistical techniques, using the Statistical Package for Social Sciences (SPSS) version 17. It is relevant to note that for the purpose of this study, the Multiple Regression Model is appropriate for our analysis of data due to the fact all the variables in this study are measured on an ordinal scale. Similarly, the choice of the Spearman's Rank Correlation Coefficient (rho) statistical technique is based on its amenability to the type and level of data that were collected in this study. 


\section{Research Results}

The table shows that the respondents considered the adaptive capacity of their organizations $(\mathrm{M}=3.79, \mathrm{SD}=0.35)$ to be slightly higher than the vulnerability of the organizations $(\mathrm{M}=3.77, \mathrm{SD}=0.34)$. Trust when viewed from its reliability dimension was found to be relatively high $(\mathrm{M}=3.77, \mathrm{SD}=0.39)$ and the highest of the three dimensions of trust. The level of trust viewed from the openness dimension $(\mathrm{M}=3.67, \mathrm{SD}=0.36)$ was slightly higher than competence dimension of trust $(\mathrm{M}=3.64, \mathrm{SD}=0.49)$. The respondents considered structure to have a slightly higher rating $(\mathrm{M}=3.74, \mathrm{SD}=0.35)$ than culture returns $(\mathrm{M}=3.71, \mathrm{SD}=0.40)$.

Table 1. Means, standard deviations and correlation of the variables

\begin{tabular}{|c|c|c|c|c|c|c|c|c|c|c|}
\hline $\mathrm{S} / \mathrm{NO}$ & Variable & Mean & $\begin{array}{l}\text { Std } \\
\text { Dev }\end{array}$ & $\begin{array}{l}\text { Organizational } \\
\text { Resilience } \\
\text { Vulnerability }\end{array}$ & $\begin{array}{l}\text { Organizational } \\
\text { Resilience } \\
\text { Adaptive } \\
\text { Capacity }\end{array}$ & $\begin{array}{l}\text { Trust } \\
\text { Competence }\end{array}$ & $\begin{array}{l}\text { Trust } \\
\text { Openness }\end{array}$ & $\begin{array}{l}\text { Trust } \\
\text { Reliability }\end{array}$ & Structure & Culture \\
\hline 1 & $\begin{array}{l}\text { Organizational } \\
\text { Resilience-Vul } \\
\text { nerability }\end{array}$ & 3.7738 & .34242 & 1.000 & & & & & & \\
\hline 2 & $\begin{array}{l}\text { Organizational } \\
\text { Resilience- } \\
\text { Adaptive } \\
\text { Capacity }\end{array}$ & 3.7905 & .35461 & $.411(* *)$ & 1.000 & & & & & \\
\hline 3 & $\begin{array}{l}\text { Trust } \quad- \\
\text { Competence }\end{array}$ & 3.6429 & .48526 & $.208(* *)$ & $.344(* *)$ & 1.000 & & & & \\
\hline 4 & $\begin{array}{l}\text { Trust } \\
\text { Openness }\end{array}$ & 3.6698 & .36309 & $.190(* *)$ & $.204(* *)$ & $.352(* *)$ & 1.000 & & & \\
\hline 5 & $\begin{array}{l}\text { Trust } \\
\text { Reliability }\end{array}$ & 3.7738 & .39437 & $.299(* *)$ & $.368(* *)$ & $.156\left(^{*}\right)$ & $.246(* *)$ & 1.000 & & \\
\hline 6 & Structure & 3.7429 & .35348 & $.555(* *)$ & $.272(* *)$ & .068 & .092 & $.349(* *)$ & 1.000 & \\
\hline 7 & Culture & 3.7143 & .39950 & $.191(* *)$ & $.362(* *)$ & $.317(* *)$ & .079 & .098 & $.148\left(^{*}\right)$ & 1.000 \\
\hline
\end{tabular}

Source: Survey Data, 2013.

** Correlation is significant at the 0.01 level (2-tailed).

* Correlation is significant at the 0.05 level (2-tailed).

The correlation among the measures of organizational resilience (vulnerability and adaptive capacity) had a coefficient of 0.411 and it was statistically significant $(\mathrm{p}<0.01)$. Among the independent variable dimensions, a total of three correlation coefficients were computed ranging from 0.156 to 0.352 . All the three coefficients were statistically significant $(2 \times \mathrm{p}<0.01$ and $1 \times \mathrm{p}<0.05)$. The correlation coefficient between structure and culture was 0.148 and it was also statistically significant. It will be observed from table 1 above that the correlation coefficients between structure and the measures of organizational resilience were 0.555 and 0.272 and both of them were statistically significant $(\mathrm{p}<0.01)$. On the other hand, the correlation between culture and the measures of organizational resilience had coefficient values of 0.191 and 0.362 . The two relationships were also statistically significant $(\mathrm{p}<0.01)$. When related to the dimensions of trust, structure had three correlation coefficients ranging from 0.068 to 0.349 . Only one of these, the relationship with reliability: 0.349 , was significant $(p<0.01)$. Between culture and the dimensions of trust, the three correlation coefficients ranged between 0.079 and 0.317 . One of these, the relationship with competence: 0.317 , was significant $(p<0.01)$. The other two were not significant.

The six correlations between the measures of organizational resilience and the dimensions of trust had coefficients ranging from 0.190 to 0.368 . These correlations were all statistically significant $(\mathrm{p}<0.01)$. The highest correlation coefficient was obtained between reliability dimension of trust and adaptive capacity measure of organizational resilience while the least was between openness dimension of trust and vulnerability measure of organizational resilience.

The following moderation tests were carried out: firstly, between each of the dependent variables (vulnerability and adaptive capacity) and the three independent variables (competence, openness and reliability) on the first level 
with the independent variables acting as the variables being controlled, and on the second level, evaluating the effect of the moderating variables, structure and culture. The moderating effect was carried out in turn for each of the moderating variables, to examine their effect on the relationship between trust dimensions and each measure of organizational resilience. Secondly, two summary multiple regression analyses were executed by constructing an overall scale for both trust and organizational resilience through obtaining the mean of the means in each case.

To evaluate the moderating effects of structure and culture on the relationship between trust and organizational resilience, a hierarchical multiple regression analysis using the simultaneous (enter) method, was carried out. As can be seen from the table above, organizational structure and corporate culture are positively and significantly related to the two measures of organizational resilience in this study (vulnerability and adaptive capacity). This therefore, qualifies them as moderating variables in this study. The discussion that follows examines the obtained results.

\subsection{Moderating Effect of Structure on the Relationship between Dimensions of Trust and Vulnerability}

The results of the key parameters for the multiple regression analysis to evaluate the moderating effect of structure on the relationship between trust dimensions and vulnerability measure of organizational resilience are presented in the table below. The table shows that both models were significant at 0.01 level of significance (Model 1: $\mathrm{F}_{3,206}=6.113, \mathrm{p}<0.01$ and Model 2: $\left.\mathrm{F}_{4,205}=21.938, \mathrm{p}<0.01\right)$. It can also be seen from the table that, taken together, the study independent variables accounted for only about $7 \%$ of the variations in vulnerability measure of organizational resilience (Model 1, Adjusted $\mathrm{R}^{2}=0.068$ ).

Table 2. Moderating effect of organizational structure on the relationship between dimensions of trust and vulnerability

\begin{tabular}{|c|c|c|}
\hline \multirow{2}{*}{ Predictors } & \multicolumn{2}{|c|}{ Vulnerability } \\
\hline & Model 1 Std $\beta$ & Model $2 \operatorname{Std} \beta$ \\
\hline \multicolumn{3}{|c|}{ Level 1: Study Independent Variables } \\
\hline Competence & 0.074 & 0.082 \\
\hline Openness & 0.122 & 0.096 \\
\hline Reliability & $0.199 *$ & 0.037 \\
\hline \multicolumn{3}{|c|}{ Level 2: Moderating Variable } \\
\hline Structure & & $0.496 * *$ \\
\hline $\mathrm{R}^{2}$ & 0.082 & 0.300 \\
\hline Adjusted $\mathrm{R}^{2}$ & 0.068 & 0.286 \\
\hline$\Delta \mathrm{R}^{2}$ & 0.082 & 0.218 \\
\hline F-Value & $6.113 * *$ & $21.938 * *$ \\
\hline$\Delta \mathrm{F}-$ Value & $6.113 * *$ & $63.817 * *$ \\
\hline
\end{tabular}

Source: Survey Data, 2013.

Note: $* * \mathrm{p}<0.01, * \mathrm{p}<0.05$.

On introducing the moderating variable, structure, adjusted $R^{2}$ increased to 0.286 , a change in $R^{2}\left(\Delta R^{2}\right)$ of 0.218 . This implies that the moderating variable contributed about $22 \%$ to explaining the variations in the vulnerability measure of organizational resilience. It is to be further observed from the table that the Standardised $\beta$ values of the study independent variables, competence and openness, were low for both models, albeit there was a marginal change in the values on introducing the moderating variable, indicating partial moderation, and they were insignificant in both models. The Standardised $\beta$ value for reliability was significant without structure $(0.199$, $\mathrm{p}<0.05)$, becoming much lower and insignificant $(0.037, \mathrm{p}>0.05)$ on the introduction of the mediating variable, indicating full moderation. The Standardised $\beta$ value for the moderating variable, organizational structure, was significant in this treatment.

\subsection{Moderating Effect of Organizational Structure on the Relationship between Dimensions of Trust and Adaptive Capacity}

An evaluation of the moderating effect of structure on the relationship between trust dimensions and adaptive capacity measure of organizational resilience was carried out. The results of the key parameters for the multiple regression analysis are presented in Table 3 below. 
Table 3. Moderating effect of organizational structure on the relationship between dimensions of trust and adaptive capacity

\begin{tabular}{lcc}
\hline \multirow{2}{*}{ Predictors } & \multicolumn{2}{c}{ Adaptive Capacity } \\
\hline Level 1: Study Independent Variables & Model 1 Std $\beta$ & Model 2 Std $\beta$ \\
\cline { 2 - 3 } Competence & & $0.169^{*}$ \\
Openness & $0.166^{*}$ & 0.032 \\
Reliability & 0.042 & $0.170^{*}$ \\
\hline Level 2: Moderating Variable & $0.230^{* *}$ & $0.185^{* *}$ \\
Structure & & 0.134 \\
$\mathrm{R}^{2}$ & & 0.117 \\
Adjusted $\mathrm{R}^{2}$ & 0.103 & 0.030 \\
$\Delta \mathrm{R}^{2}$ & 0.090 & $7.909^{* *}$ \\
F-Value & 0.103 & $7.166^{* *}$ \\
$\Delta$ F-Value & $7.920^{* *}$ & $7.920^{* *}$ \\
\hline
\end{tabular}

Source: Survey Data, 2013.

Note: ${ }^{* *} \mathrm{p}<0.01,{ }^{*} \mathrm{p}<0.05$.

From the table, it can be seen that the two models under consideration were significant at 0.01 level of significance (Model 1: $\mathrm{F}_{3,206}=7.920, \mathrm{p}<0.01$ and Model 2: $\mathrm{F}_{4,205}=7.909, \mathrm{p}<0.01$ ). We also observe that the independent variables, taken together, accounted for only $9 \%$ of the variations in adaptive capacity measure of organizational resilience (Model 1, Adjusted $\mathrm{R}^{2}=0.090$ ). On the introduction of the moderating variable, structure, into the model, Adjusted $\mathrm{R}^{2}$ marginally increased to 0.117 , to present a marginal additional $2.7 \%$ explanation in the variations in adaptive capacity measure of organizational resilience. The standardised $\beta$ values of the study independent variables, competence and reliability, were significant in both models, albeit with marginal changes from model 1 to model 2 demonstrating partial moderation by structure. The same situation subsisted for the predictor variable, openness, but the Standardised $\beta$ values were insignificant in both models. The Standardised $\beta$ value for the moderating variable, organizational structure, was also significant in this action.

4.3 Moderating Effect of Organizational Structure on the Relationship between Trust and Organizational Resilience (Overall Scale)

A further attempt was made to construct an overall scale for both trust and organizational resilience through obtaining the mean of the means in each case. Through this way, the mean and standard deviation of the overall measure of organizational resilience were computed to be 3.7821 and 0.286 respectively while those for the overall measure of trust were 3.6955 and 0.2912 . The multiple regression key parameters, with structure as moderating variable, are presented in the table below.

The table shows that the models were significant without and with the moderating variable (Model 1: $F_{1,208}=28.648, p<0.01$ and Model 2: $F_{2,207}=40.850, p<0.01$ ). It is relevant to note that there were changes in the model parameters (Standardised $\beta$ value, Adjusted $\mathrm{R}^{2}$ and $\mathrm{F}$-Value) from Model 1 (without moderating variable) to Model 2 (with moderating variable). This indicates the moderating role of organizational structure in the relationship between trust and organizational resilience. From Model 1, we can observe that trust explains about $12 \%$ of the variations in organizational resilience (Model 1 , Adjusted $\mathrm{R}^{2}=0.117$ ). On the introduction of organizational structure into the model, Adjusted $\mathrm{R}^{2}$ increased to 0.276 implying that organizational structure contributed additional $16 \%$ to explaining the variations in organizational resilience. 
Table 4. Overall moderating effect of organsational structure on the relationship between trust and organizational resilience

\begin{tabular}{|c|c|c|c|}
\hline \multirow{2}{*}{ Predictors } & & \multicolumn{2}{|c|}{ Organizational Resilience } \\
\hline & & Model 1 Std $\beta$ & Model $2 \operatorname{Std} \beta$ \\
\hline \multicolumn{4}{|c|}{ Level 1: Study Independent Variable } \\
\hline Trust & & $0.348 * *$ & $0.251 * *$ \\
\hline \multicolumn{4}{|c|}{ Level 2: Moderating Variable } \\
\hline Structure & & & $0.414 * *$ \\
\hline & $\mathrm{R}^{2}$ & 0.121 & 0.283 \\
\hline & Adjusted $\mathrm{R}^{2}$ & 0.117 & 0.276 \\
\hline & $\Delta \mathrm{R}^{2}$ & 0.121 & 0.162 \\
\hline & F-Value & $28.648 * *$ & $40.850 * *$ \\
\hline & $\Delta \mathrm{F}-$ Value & $28.648 * *$ & $46.749 * *$ \\
\hline
\end{tabular}

Source: Survey Data, 2013.

Note: $* * \mathrm{p}<0.01, * \mathrm{p}<0.05$.

The standardised $\beta$ value of trust was significant in both models. It reduced from 0.348 to 0.251 on introducing organizational structure into the model. This indicates the moderating role of organizational structure in the relationship between trust and organizational resilience. It is also relevant to note that the standardised $\beta$ value of structure was significant in model 2.

4.4 Moderating Effect of Corporate Culture on the Relationship between Dimensions of Trust and Vulnerability

A multiple regression analysis to evaluate the moderating effect of corporate culture on the relationship between trust dimensions and vulnerability measure of organizational resilience was also carried out. The results for the key parameters are presented in the table below.

Table 5. Moderating effect of corporate culture on the relationship between dimensions of trust and vulnerability

\begin{tabular}{lll}
\hline \multirow{2}{*}{ Predictors } & \multicolumn{2}{c}{ Vulnerability } \\
\cline { 2 - 3 } Level 1: Study Independent Variables & Model 1 Std $\beta$ & Model 2 Std $\beta$ \\
Competence & & 0.040 \\
Openness & 0.122 & 0.121 \\
Reliability & $0.199^{*}$ & $0.189^{*}$ \\
\hline Level 2: Moderating Variable & & 0.123 \\
Culture & & 0.095 \\
$\mathrm{R}^{2}$ & 0.082 & 0.078 \\
Adjusted $\mathrm{R}^{2}$ & 0.068 & 0.014 \\
$\Delta \mathrm{R}^{2}$ & 0.082 & $5.405^{* *}$ \\
F-Value & $6.113^{* *}$ & 3.092 \\
$\Delta$ F-Value & $6.113^{* *}$ & \\
\hline
\end{tabular}

Source: Survey Data, 2013.

Note: ${ }^{* *} \mathrm{p}<0.01, * \mathrm{p}<0.05$.

From the table, it is observed that both models were significant (Model 1: $F_{3,206}=6.113, p<0.01$ and Model 2: $\left.\mathrm{F}_{4,205}=5.405, \mathrm{p}<0.01\right)$. The $\mathrm{F}$ - Change $(\Delta \mathrm{F}-$ Value $)$ was however, insignificant in Model 2. It can also be seen that the independent variables, taken together, accounted for $6.8 \%$ of the variations in the vulnerability measure of organizational resilience (Model 1, Adjusted $\mathrm{R}^{2}=0.068$ ). On the introduction of the moderating variable, culture, Adjusted $\mathrm{R}^{2}$ marginally rose to 0.078 (Model 2) suggesting that culture contributed $1 \%$ to explaining the variations in the vulnerability measure of organizational resilience. The Standardised $\beta$ value of reliability dimension was significant in both models, decreasing from 0.199 to 0.189 on introducing culture into the model. This implies a partial moderation of its relationship with the vulnerability measure of organizational resilience. The Standardised $\beta$ values for competence and openness were insignificant in the two models. For competence, full mediation was apparent given the over $45 \%$ change in the standardised $\beta$ value from 0.074 in model 1 to 0.040 in model 2 , on the 
introduction of culture into the model. The moderating effect of culture on the relationship between openness and the vulnerability measure of organizational resilience was only partial or perhaps non-existent, given the marginal change in the standardised $\beta$ value from 0.122 in model 1 to 0.121 in model 2 . The Standardised $\beta$ value for the moderating variable, culture, was insignificant in this action.

\subsection{Moderating Effect of Corporate Culture on the Relationship between Dimensions of Trust and Adaptive Capacity}

The results of the multiple regressions performed to examine the moderating effect of culture on the relationship between trust dimensions and adaptive capacity measure of organizational resilience are presented in Table 6 below.

Table 6. Moderating effect of corporate culture on the relationship between dimensions of trust and adaptive capacity

\begin{tabular}{lll}
\hline \multirow{2}{*}{ Predictors } & \multicolumn{2}{c}{ Adaptive Capacity } \\
\cline { 2 - 3 } Level 1: Study Independent Variables & Model 1 Std $\beta$ & Model 2 Std $\beta$ \\
Competence & & $0.166^{*}$ \\
Openness & 0.042 & 0.056 \\
Reliability & $0.230^{* *}$ & $0.198^{* *}$ \\
\hline Level 2: Moderating Variable & & $0.399^{* *}$ \\
Culture & & 0.248 \\
$\mathrm{R}^{2}$ & 0.103 & 0.234 \\
Adjusted $\mathrm{R}^{2}$ & 0.090 & 0.145 \\
$\Delta \mathrm{R}^{2}$ & 0.103 & $16.922^{* *}$ \\
F-Value & $7.920^{* *}$ & $39.491^{* *}$ \\
$\Delta \mathrm{F}-$ Value & $7.920^{* *}$ & \\
\hline
\end{tabular}

Source: Survey Data, 2013.

Note: $* * \mathrm{p}<0.01, * \mathrm{p}<0.05$.

From the table, it can be seen that the two models were significant at 0.01 level of significance (Model 1: $\mathrm{F}_{3,206}=7.920, \mathrm{p}<0.01$ and Model 2: $\left.\mathrm{F}_{4,205}=16.922, \mathrm{p}<0.01\right)$. We also observe that the independent variables, taken together, accounted for only $9 \%$ of the variations in adaptive capacity measure of organizational resilience (Model 1 , Adjusted $\mathrm{R}^{2}=0.090$ ). With the introduction of the moderating variable, culture, into the model, Adjusted $\mathrm{R}^{2}$ increased to 0.234 , to present an additional $14.5 \%\left(\Delta \mathrm{R}^{2}=0.145\right)$ explanation to the variations in adaptive capacity measure of organizational resilience. The standardised $\beta$ value of the study independent variable, reliability, was significant in both models, but it reduced from 0.230 in model 1 to 0.198 in model 2 indicating partial moderation by culture. For competence dimension, full moderation was evident as the standardised $\beta$ value reduced by over $66 \%$ from 0.166 in model 1 to 0.056 in Model 2, and it was significant in model 1 but became insignificant in Model 2 when culture was introduced. For the predictor variable, openness, the Standardised $\beta$ values were insignificant in both models and the change in value was marginal signifying partial moderation by culture. The Standardised $\beta$ value for the moderating variable, corporate culture, was also significant in this analysis.

4.6 Moderating Effect of Corporate Culture on the Relationship between Trust and Organizational Resilience (Overall Scale)

A further attempt was made to construct an overall scale for both trust and organizational resilience through obtaining the mean of the means in each case. As already presented, the mean and standard deviation of the overall measure of organizational resilience were computed to be 3.7821 and 0.286 respectively while those for the overall measure of trust were 3.6955 and 0.2912 respectively. The key parameters of the overall multiple regression results, with culture as moderating variable, are presented in Table 7 below. 
Table 7. Overall moderating effect of corporate culture on the relationship between trust and organizational resilience

\begin{tabular}{lcc}
\hline \multirow{2}{*}{ Predictors } & \multicolumn{2}{c}{ Organizational Resilience } \\
\cline { 2 - 3 } Level 1: Study Independent Variable & Model 1 Std $\beta$ & Model 2 Std $\beta$ \\
Trust & $0.348^{* *}$ & $0.265^{* *}$ \\
\hline Level 2: Moderating Variable & & $0.308^{* *}$ \\
Culture & & 0.209 \\
$\mathrm{R}^{2}$ & 0.121 & 0.202 \\
Adjusted $\mathrm{R}^{2}$ & 0.117 & 0.088 \\
$\Delta \mathrm{R}^{2}$ & 0.121 & $27.373^{* *}$ \\
F-Value & $28.648^{* *}$ & $23.060^{* *}$ \\
\hline F-Value & $28.648^{* *}$ & \\
\hline
\end{tabular}

Source: Survey Data, 2013.

Note: $* * \mathrm{p}<0.01,{ }^{*} \mathrm{p}<0.05$.

The table shows that the models were significant in both cases (Model 1: $\mathrm{F}_{1,208}=28.648, \mathrm{p}<0.01$ and Model 2: $\mathrm{F}_{2,207}=27.373, \mathrm{p}<0.01$ ). It can be seen that there were changes in the model parameters (Standardised $\beta$ value, Adjusted $\mathrm{R}^{2}$ and F-Value) from Model 1 (without moderating variable) to Model 2 (with moderating variable) to indicate moderation by culture in the relationship between trust and organizational resilience. From Model 1, we can observe that trust explained about $12 \%$ of the variations in organizational resilience (Model 1, Adjusted $\mathrm{R}^{2}=$ 0.117 ). On the introduction of culture into the model, Adjusted $\mathrm{R}^{2}$ increased to 0.202 meaning that culture contributed additional $8 \%$ to explaining the variations in organizational resilience. The standardised $\beta$ values of trust were significant in both models. It however, reduced from 0.348 to 0.265 on introducing.

Table 8. Synopsis of the results of the moderating effects of structure and culture on the relationship between trust and organizational resilience

\begin{tabular}{|c|c|c|c|c|c|c|c|c|c|c|}
\hline \multirow{4}{*}{ Predictors } & & \multicolumn{9}{|c|}{ Criterion Variables } \\
\hline & & \multicolumn{3}{|c|}{ Vulnerability } & \multicolumn{3}{|c|}{ Adaptive Capacity } & \multicolumn{3}{|c|}{ Organizational Resilience } \\
\hline & & & & $\Delta \mathrm{R}^{2}$ & & & $\Delta \mathrm{R}^{2}$ & & & $\Delta \mathrm{R}^{2}$ \\
\hline & & $\beta_{1}$ & $\beta_{2}$ & $\begin{array}{l}\text { Moderating } \\
\text { Effect }\end{array}$ & $\beta_{1}$ & $\beta_{2}$ & $\begin{array}{l}\text { Moderating } \\
\text { Effect }\end{array}$ & $\beta_{1}$ & $\beta_{2}$ & $\begin{array}{l}\text { Moderating } \\
\text { Effect }\end{array}$ \\
\hline MODERATION & WITH & & & & & & & & & \\
\hline STRUCTURE & & & $0.496^{* *}$ & 0.218 & & $0.185^{* *}$ & 0.030 & & $0.414^{* *}$ & 0.161 \\
\hline 1. Competence & & 0.074 & 0.082 & Partial & $0.166^{*}$ & $0.169^{*}$ & Partial & & & \\
\hline 2. Openness & & 0.122 & 0.096 & Partial & 0.042 & 0.032 & Partial & & & \\
\hline 3. Reliability & & $0.199 *$ & 0.037 & Full & $0.230 * *$ & $0.170^{*}$ & Partial & & & \\
\hline Overall: Trust & & & & & & & & $0.348^{* *}$ & $0.251^{* *}$ & Full \\
\hline MODERATION & WITH & & & & & & & & & \\
\hline CULTURE & & & 0.123 & 0.014 & & $0.399^{* *}$ & 0.145 & & $0.308^{* *}$ & 0.088 \\
\hline 1. Competence & & 0.074 & 0.040 & Full & $0.166^{*}$ & 0.056 & Full & & & \\
\hline 2. Openness & & 0.122 & 0.121 & Partial & 0.042 & 0.037 & Partial & & & \\
\hline 3. Reliability & & $0.199 *$ & $0.189^{*}$ & Partial & $0.230^{* *}$ & $0.198^{* *}$ & Partial & & & \\
\hline Overall: Trust & & & & & & & & $0.348 * *$ & $0.265^{* *}$ & Full \\
\hline
\end{tabular}

Source: Survey Data, 2012;

$\beta_{1}=$ Without Moderation, $\beta_{2}=$ With Moderation, ${ }^{*} \mathrm{p}<0.01,{ }^{*} \mathrm{p}<0.05$.

Culture into the model, to indicate moderation of the relationship between trust and organizational resilience. The Standardised $\beta$ value for the moderating variable, culture, was also significant in this analysis.

In summary, it can be seen from the results of data analysis that both organizational structure and corporate culture moderate the relationship between trust and organizational resilience. In other words, trust has an indirect impact on organizational resilience via structure and culture. 


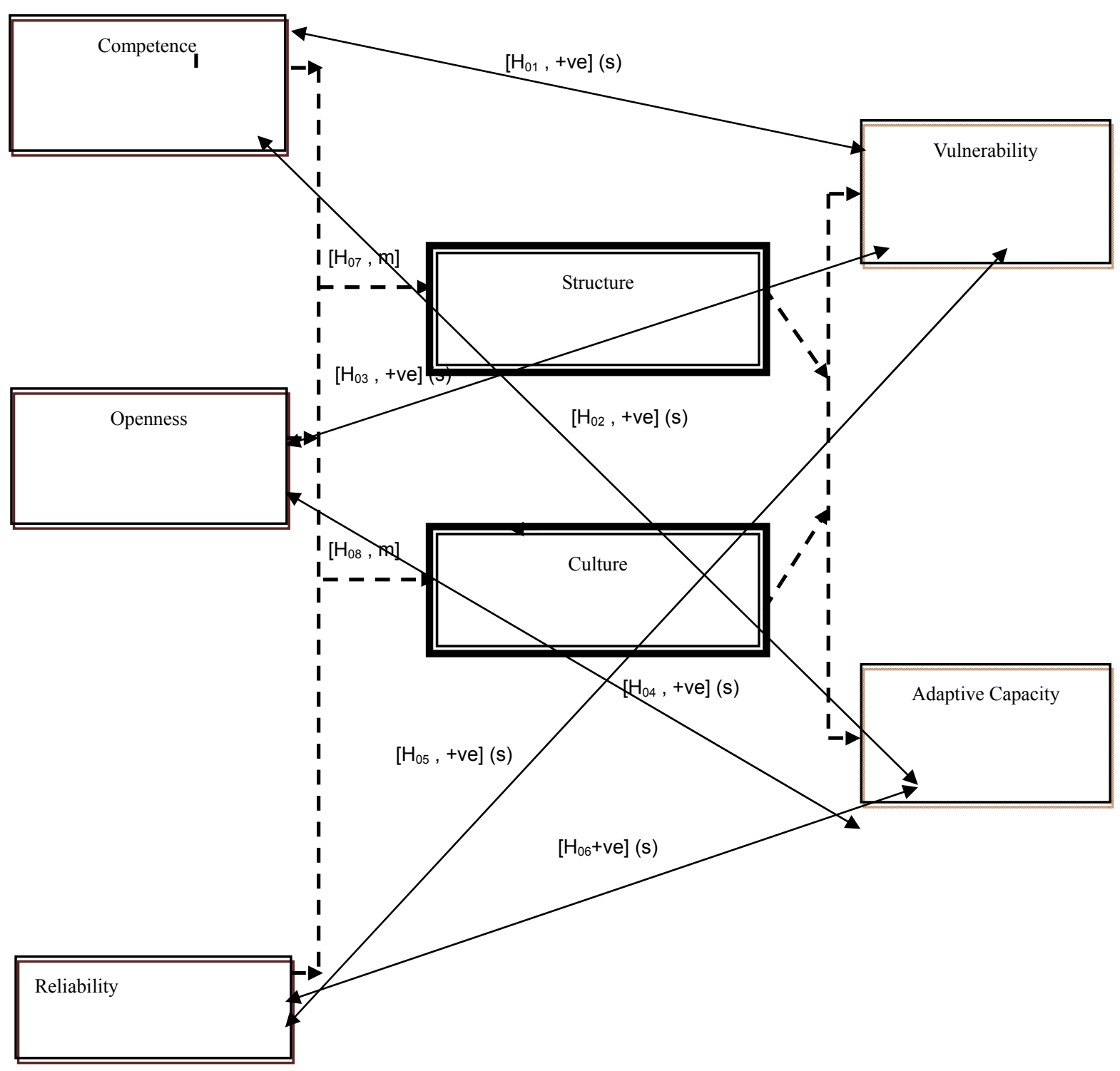

Figure 2. Empirical results of the effect of trust on organizational resilience

Note: $\mathrm{S}=$ significant; $m=$ moderates.

\section{Discussion of Findings and Conclusions}

\subsection{Competence and Vulnerability}

The results of data analysis revealed a positive and significant relationship between competence and vulnerability. This implies that Competence boosts or enhances organizational vulnerability. One possible explanation for this finding may be that when the members of staff perceive their organization as capable of meeting their needs both now and in the foreseeable future, it creates affective feelings in the workers. This may in turn motivate them to make contributions towards enhancing the vulnerability of the organization, with the belief and conviction that the survival of the organization is their survival as well. Clearly therefore, an organization that has an effective leader and is also able to survive in the market place (a competent organization) will operate in a favourable vulnerability position thus enhancing the survival of the organization in the face of any threats. This is the result we have found out in this study. This position is buttressed by Posen (2011) who argues that where the members believe in the competence of the organization, they give their all to ensure that the organization is protected thus making the organization less vulnerable to disasters. It also aligns with the position of Shockley-Zalabak et al (2011b) who argues that competence had proven to be statistically significant in creating favourable vulnerability for an organization. 


\subsection{Competence and Adaptive Capacity}

Similarly, the result of data analysis also revealed a positive and significant and relationship between competence and adaptive capacity. This implies that competence advances, boosts or enhances organizational adaptive capacity. This finding may be explained by the fact that competence is promoted through continuous learning and this capability precedes and underlies innovation, execution, and adaptive or pre-emptive response. To this end, when an organization is perceived as having the ability for collective learning and is seen as being able to survive, there is an adaptive capacity response generated in the members, thus promoting the organization's adaptive capacity. We may also view this relationship as being further enhanced given the individual need for security. Every employee wants to have a secured feeling and in this process may recognise that his security depends on the secured position of the organization exemplified by its adaptive capacity. With an assurance of the organization's competence, the members may be motivated to contribute to its adaptive capacity both for their survival and the organization's survival as well, a symbiosis beneficial to both parties. This underlies the connection between competence and adaptive capacity of organizations. For an organization to be able to continuously improve on its ability and speed to manage crises effectively (adaptive capacity), then the competence of its leaders and of the organization itself is of the essence. This result is in line with the position offered by Clark and Gottfredson (2008) when they averred that the ultimate source of adaptive capacity, competitiveness, and self-preservation, indeed the key to resilience and renewal, unmistakably points to the ongoing ability of an organization to learn and apply its knowledge, which is a measure of its competence.

\subsection{Openness and Vulnerability}

The result of data analysis revealed a positive and significant relationship between openness and an organization's vulnerability. This implies that openness enhances organizational vulnerability. This finding may be explained by the fact that workers perceive openness as being indicative of mutually-serving rather than self serving motives. Consequently, they are inspired to give of their best believing that it is also for their own good if improvements result in desirable organizational outcomes. This plays out to enhance the vulnerability of the organization. The converse to an open organization may be one that breeds distrust and withdrawal with its adverse consequences on desirable organizational outcomes over the long run. The significant relationship between openness and vulnerability may also be explained by the fact that openness breeds positive relationships which have been known to serve as the key coping resources that enables individuals and organizations to develop resilience in the face of work stress and the attacks. Moreover, people cannot be taken for granted if they are to give of their best. When they are fed with trusted information from a trusted source, that supports known facts, they are encouraged to continue to make meaningful contributions to the enhancement of the vulnerable positions of the organization.

This finding is consistent with the earlier findings of Shockley--Zalabak et al. (2011a) who found that openness is a major determinant of organizational vulnerability, and in particular, the adaptive capacity. It was their contention that when the leadership's efforts are perceived as being sincere, judged by the communication shared across the organization, the organization members develop increased levels of commitment which positively impacts on the vulnerability of the organization. This is very significant as it has been proven that the level of communication sharing in an organization dictates the extent to which the organization becomes open and can be trusted by its members (Ouchi, 1981; Shockley--Zalabak, 1999; Nanus, 1989). Similarly, Berkes and Folke (2002) also conjectured that enhancing openness in the organization through communication breeds confidence in the workforce and galvanises contributions towards enhancing the organization's vulnerable position in the event of an adverse situation or condition.

\subsection{Openness and Adaptive Capacity}

The result of data analysis revealed a positive and significant relationship between openness and an organization's adaptive capacity. This finding implies that openness enhances an organization's adaptive capacity. This finding may be explained by the fact that feeling of belonging is accentuated by the creation of openness within an organization. Adaptive capacity, which depends on the ability of a society or organization to act collectively, and to resolve conflicts between its members, is a factor that is heavily influenced by governance and the creation of openness in the organization. If these systems were not put into motion, there is a much greater likelihood of panic in the event of an untoward situation. This finding may also be explained by the fact that openness breeds appreciation and reduces rumours. Where people are well informed of happenings around them without having to dig deep to get the information they require, they are encouraged to give of their best. Moreover, suspicions will be reduced to the barest minimum thus engendering mutual coexistence and identification with the objectives of the organization. This result is in line with the findings of earlier studies on the relationship between the two variables. The earlier study of Berkes and Folke (2002) revealed that trusted communication will allow the 
organization and individuals within it to adapt more quickly. On their part, Spreitzer and Mishra (1999) argued that involving lower echelon of employees in the decision making process is a measure of the organization's openness and this enhances various desirable organizational outcomes including adaptive capacity. Similarly, Holling and Gunderson (2002) also corroborated this view as they suggested that openness increases the potential for continuous change and enhances the adaptive cycle of the organization. Resilience in a situation like a hurricane or pandemic or other untoward attacks, requires that individuals and organizations create openness through trusted information from a central source that can see the whole picture; and to contact individuals to ascertain damage to specific people and assets. This view was also supported by Samarajiva (2005). This will demonstrate the adaptive capacity of the organization built through a network of trusted information disseminators that have been established within the culture of openness established before the event.

\subsection{Reliability and Vulnerability}

The result of data analysis shows that there is a positive and significant relationship between reliability and an organization's vulnerability. This implies that reliability does enhance vulnerability. A possible explanation for this result is that relationships in an organization are enhanced when the members do not develop a feeling of negative inequity in the decisions they are exposed to in the organization. When everyone has a feeling of being fairly treated in his experiences and in all circumstances, they will not waste valuable time in questioning decisions and actions, thus getting dissatisfied, disillusioned or discouraged. Such discouragement may lead to "switching off" with its adverse consequences on desirable organizational outcomes. Furthermore, a person's perception of unjust treatment, such as in the application of personnel policies and practices, or in reward management and punishment systems, can lead to tension and conflict. The perception of inequity will motivate a person to take action to restore equity, including changes to inputs or outputs, or through acting on others. This will ultimately lead to distortions in the system including deteriorated level of vulnerability. Variations in the consistency of various standards within an organization can quickly lead to a feeling of dissatisfaction and perceived injustice. This finding is in agreement with the earlier finding of Gittelle (2003) which indicates that inconsistent and erratic behaviours will pave the way for negative performance outcomes and these effects are consistent with relational theory, which suggests that relationships are an important predictor of organizational outcomes. Gittelle (2003) also posited that in the determinant of vulnerability, reliable behaviours will engender positive contributions from the workforce. Gittelle (2003) further affirmed that organizations which have developed relationships which were built on consistent and dependable behaviours, particularly in decision making and reward distribution, were able to identify their exposure levels prior to the terrorist attacks of September 11, 2001 thus enhancing their level of vulnerability. To further understand the need for consistency and dependability in enhancing vulnerability, Dalziell and McManus (2011) introduced systems analysis to explain the relationship. Accordingly, Dalziell and McManus (2011), argues that a key concept within systems analysis is the recognition that "the whole is greater than the sum of its parts" and hence, the emergent properties of a system cannot be understood by analysing the components of the system in isolation. It may not be possible to understand the way that a team of people work together by analysing the way that they work in isolation. By interacting with each other, each person will naturally modify their behaviour to respond to their colleague's ideas, mood, and actions. Similarly, the effectiveness of any organization is a function of not only how effective each of its individual departments are, but also on how well these departments work together for the good of the organization. These call for reliability in behaviour. The foregoing may also explain why it is expedient that organizations exhibit reliable behaviours if vulnerability is to be enhanced.

\subsection{Reliability and Adaptive Capacity}

The result of data analysis revealed a positive and significant relationship between reliability and an organization's adaptive capacity. This implies that reliability enhances or promotes an organization's adaptive capacity. This finding may be explained by the fact that as workers continue to perceive reliable behaviours in their organizations, they perceive and/or experience a feeling of fairness and justice. As a result, they are moved to continue to contribute to the organization's performance and this ultimately affects the adaptive capacity of the organization. As previously stated, a feeling of negative inequity distorts the equilibrium of an organization and negatively impacts on organizational outcomes. When organizations are consistent in selecting, hiring, evaluating and rewarding people based on their ability to thrive, they enhance the willingness and ability of organizational members to make meaningful contributions towards enhancing the adaptive capacity of organizations. This result is in conformity with the obtained results by previous researches in this area. To affirm the place of reliability in developing the adaptive capacity of organizations, Brooks and Adger (2011) averred that further constraints on developing adaptive capacity might be the result of internal conflict (e.g., mitigating against long-term planning and/or investment and preventing regional co-operation). Similarly, the finding of Smit and 
Wandel (2006) indicates that for adaptive capacity to be enhanced, it is imperative that organizational behaviours be consistent over time. In their opinion, a system's adaptive capacity and coping range (one feature of capacity) are not static. Coping ranges are flexible and respond to changes in economic, social, political and institutional conditions over time, thus requiring consistent behaviours in order to continually reap adaptive capacity levels attained (Smit \& Wandel, 2006).

\subsection{Moderating Effects of Organizational Structure and Corporate Culture on the Relationship between Trust and Organizational Resilience}

The result of data analysis revealed that organizational structure significantly moderates the relationship between trust and organizational resilience. Specifically, organizational structure exhibited direct and significant relationships with the measures of the criterion variable (organizational resilience) in this study (that is vulnerability and adaptive capacity). This implies that organizational structure significantly moderates the relationship between trust and organizational resilience.

Structure is associated with efforts to achieve both individual needs and organizational goals (Mullins, 2005) which facilitates the release of the best spirit for accomplishment from the individuals in the organization. It is believed that the structure of an organization has a telling effect on the feeling of belonging of employees and their readiness to contribute meaningfully to the achievement of an organization's goals and objectives (Mullins, 2005). This may have been responsible for the result obtained regarding the moderating effect of structure on the relationship between trust and organizational resilience. Where employees have a sense of belonging on their job and believe they are putting their skills and abilities to full use, they will be moved to give their best. This can only be achieved through designing a structure that is symbiotic, considering the needs of the employees in relation to the objectives of the organization. When such an environment subsists, the employees feel a sense of gratitude to the organization, trust it, and this generates a quantum reaction on the resilience of the organization. This result is in conformity with the view expressed by Clark and Gottfredson (2008) when they considered that the relentless disruption of the 80's had made it clear that organizational survival depended on learning as an ongoing process and putting proper structures in place to meet the challenges. As thousands of low-skill manufacturing jobs began migrating overseas, industry leaders had no choice but to move up the value chain and place more emphasis on knowledge work obtained results, if the organization was to survive. This extols the place of structure in achieving favourable organizational outcomes. This realisation had led many organizations to move some distance from an industrial, hierarchical model to one with delayered management and employee empowerment practices. Knowledge workers had slowly persuaded organizations to create more flexible lattice-like structures. They also prompted a revolution in the concepts of performance and career, demanding that organizations spend more time training and supporting their employees and less time directing them. The idea that individuals and teams could largely be self-directed was also introduced, as was the concept of continuous improvement (Senge, 1990; Mullins, 2005).

Similarly, the result of data analysis also revealed that corporate culture significantly moderates the relationship between trust and organizational resilience. This implies that culture significantly moderates the relationship between trust and organizational resilience. This result agrees with previous studies in this regard. Cartwright (1999) had suggested that when accepted by employees, cultural values increase the power and authority of management in several ways. Employees identify themselves with their organization and accept its rules when it is the right thing to do. In addition, employees internalise the organization's values when they believe they are right and they are motivated to achieve the organizations objectives. As propounded by Schein (2000), the basic assumptions are treated as the essence-what culture really is; and values and behaviours are treated as observed manifestations of the culture essence, which directs behaviour. The finding in this study may be explained by the fact that an organization's culture has a telling effect on the attitudes and the dispositions of its employees to make meaningful contributions to the organization. As culture is reinforced through the system of rites and rituals, patterns of communication, the informal organization, expected patterns of behaviour and perceptions of the psychological contract, employees would want to align with the way things are done in the organization once they are integrated into it. Subsisting culture in the organization will affect the way employees relate with one another and without doubt, relational reserves are important ingredients in building trust and organizational experiences. In this light, Gittelle, (2003) had suggested that inconsistent and erratic behaviours will pave the way for negative performance outcomes and these effects are consistent with relational theory, which suggests that relationships are important predictors of organizational outcomes. Gittelle, (2003) also argued that in the determinant of vulnerability, reliable behaviours will engender positive contributions from the workforce, which takes us back to the subsisting culture in the organization. It must be emphasized that developing organizational cultures that are underpinned by ethical behaviour, engenders trust and builds resilience. 


\section{Recommendations}

Based on the discussion of findings and conclusions above, the following recommendations are made in order to enhance the resilience of organizations for the preservation of the going concern of the organization and facilitate the achievement of organizational objectives. Firstly, enterprise managers must appreciate the fact that a system design approach that emphasises resilience as an inherent organic property rather than an abstract goal is desirable. Secondly, management of the Nigerian oil and gas industry should demonstrate trust-building behaviours towards building a supportive work environment which is indispensable in attempts to build a resilient organization. Thirdly, a learning organization where every organizational member flows together is imperative. Through learning, awareness is created thus enhancing the pursuit of a resilient organization. In addition, effective communication of corporate direction with clarity and consistency to all employees who have a right and need to know will promote the creation of a resilient organization. Fourthly, the management of the Nigerian oil and gas industry should recognise the fact that leadership for resilience demands that leadership be responsible, responsive, imaginative and transformative. Organization leaders need to device means of encouraging innovation, building in flexibility, strengthening and broadening connection networks, building a sense of purpose and managing employee stress. Leaders have to ensure that every viewpoint is respected, not allowing custodians of convention in the organization to censor such views. Fifthly, the leadership, in a quest for a resilient organization, should take cognisance of conditions impacting its roles and be prepared to invent ways of ameliorating the possible effects of such conditions. These conditions include greater cultural diversity, increased impact and use of technology, organizational culture, organizational structure, employee concerns for greater independence and autonomy and the need for ethical standards that are clear, unambiguous and consistent. Sixthly, management of the Nigerian oil and gas industry should recognize the fact that people are key to the success of any organization. Adequate attention should be given to managing knowledge in order to reap the full benefits of a committed workforce that is innovative and inventive. Employee development should be seen as an investment not a cost. This way, identifying vulnerability, adapting and growing the business will be fun for everyone. Seventhly, structures should be put in place to facilitate the voluntary commitment of employees to the need for building a resilient organization. Such structures include room for self expression, consultation and freedom to make decisions of varying degrees by various strata of employees. Employees should be empowered and the appropriate authority levels properly communicated. Eighthly, in managing people, a positive motivational climate where employees take responsibility for their own motivation and performance should be created. In addition, employees want to have a feeling of belonging and importance. They would also like to be appreciated, recognized and validated for their performance. Lastly, it is expedient that organizations be proactive in building structures aimed at achieving the resilience of their organizations. It serves no useful purpose waiting for disasters to happen before planning for them. Relationships should be established and authorities clearly spelt out before hand. This will enhance the resilience of the organizations in the event of a disaster.

\section{References}

Agbaje, O. (2010). Does Nigeria Need a Revolution? Business Day, 48.

Agbonsuremi, O. (2012). Political Platform. Ray Power Radio Programme.

Aston, L. (2011). Organizational Resilience. Retrieved from http://www.onrec.com/news/news-archive/developing-organizational-and-individual-r

Baridam, D. M. (2001). Research Methods in Administrative Sciences (3rd ed.). Port Harcourt: Sherbrooke Associates.

Bass, B. M. (1992).Stress and Leadership. Decision Making and Leadership. Cambridge: Cambridge University Press.

Berkes, F., \& Folke, C. (2002). Back to the Future: Ecosystem Dynamics and Local knowledge. In Gunderson, L. H., \& Holling, C. S. (Eds.), Panarchy: Understanding Transformations in Human and Natural Systems (pp. 121-146). Washington, D. C., USA: Island Press.

Bhattacharya, R., Devinney, T. M., \& Pillutla, M. M. (1998). A Formal Model of Trust Based on Outcomes. Academy of Management Review, 23, 459-472.

Bodnarczuk, M. (2008). The Organizational Trust Index as a Window into Organizational Culture. Retrieved from http://ezinearticles.com/?The--Organizational-Trust-Index-as-a-Window--into-Organizational-Cultureandid $=1085113$ 
Bright, F. (2011). The Mix: Oil and Water!: Nigerian Marginal Field. Retrieved from $\mathrm{http}: / /$ www.themixoilandwater.com/2011/05/nigerian-marginal-fields-n

Brooks, N., \& Adger, W. N. (2011). Assessing and Enhancing Adaptive Capacity. Retrieved from http://www.undp.org/GEF/documents/publications/apf-technical-paper07.pdf

Butler, J. K. Jr. (1991). Towards Understanding and Measuring Conditions of Trust: Evolution of Conditions for Trust Inventory. Journal of Management, 17, 643-663. http://dx.doi.org/10.1177/014920639101700307

Cartwright, J. (1999). Cultural Transformation. Financial Times Prentice Hall, 34.

Ceridian, A. (2011). How Managers Can Build Organizational Resiliency. Retrieved from http://www.hrmreport.com/article/How-Managers-Can-Build-Organizational-Resiliency/

Clark, T. R., \& Gottfredson, C. A. (2008). In Search of Learning Agility: Assessing Progress from 1957 to 2008. Retrieved from http://www.astd.org/NR/rdonlyres/218AD515-A30C-40FC-BFB6-789AFE

Claudio-Pascua, V. V. (2011). Organizational Resilience: Building Your Organization to Last. Retrieved from http://66.179.232.89/pdf/ddi_ph_pmap_resilience_ar.pdf

Cummings, L. L., \& Bromiley, P. (1996). The Organizational Trust Inventory (OTI): Development and Validation. In R. M. Kramer \& T R. Tyler (Eds.), Trust in Organizations: Frontiers of Theory and Research (pp. 302-330). Thousand Oaks: Sage. http://dx.doi.org/10.4135/9781452243610.n15

Dalziell, E. P., \& McManus, S. T. (2011). Resilience, Vulnerability, and Adaptive Capacity: Implications for System Performance. Retrieved from http://citeseerx.ist.psu.edu/viewdoc/download?doi=10.1.1.110.1774\&rep=rep1\&type=pdf

Denison, D. R. (1990). Corporate culture and organizational effectiveness. New York: John Wiley and Sons.

Ellis, K., \& Shockley-Zalabak, P. (1999). Organizational Trust across Cultures: the Development and Validation of an Instrument and A Study of the Relationship to Job Satisfaction and Perceived Organizational Effectiveness. In Shockley-Zalabak, P., Ellis, K., \& Winograd, G. (Eds.), Organizational Trust: What It Means, Why it Matters.

Feather, K. (2011). Techniques for Improving Organizational Resilience. Retrieved from http://employeeengagement.ning.com/profiles/blog/show?id=1986438\%3ABlogPost

Freund, J. E., \& Williams, F. J. (1979). Modern Business Statistics (2nd ed.). London: Pitman Publishing Limited.

Fukuyama, F. (1995). Trust: The Social Virtues and the Creation of Prosperity. New York: Free Press.

Gittelle, J. H. (2003). The Southwest Airlines Way: Using the Power of Relationships to Achieve High Performance. New York: McGraw-Hill.

Gittelle, J. H., Cameron, K., \& Lim, S. G. P. (2005). Relationships, Layoffs, and Organizational Resilience: Airline Industry. Retrieved from http://www.bus.umich.edu/...Org\%20Resilience\%20Jan\%2005.pdf

Hage, J., \& Aiken, M. (1967). Relationship of centralization to other structural properties. Administrative Science Quarterly, 72-92. http://dx.doi.org/10.2307/2391213

Hall, R. H. (1991). Organizations: Structures, processes, and outcomes. Prentice Hall, Englewood Cliffs.

Holling, C. S., \& Gunderson, L. H. (2002). Resilience and Adaptive Cycles. In Gunderson, L. H., \& Holling, C. S. (Eds.), Panarchy: Understanding Transformations in Human and Natural Systems (pp. 25-62). Washington, D. C., USA: Island Press.

Horne, J. F. (1997). The Coming Age of Organizational Resilience. Retrieved from $\mathrm{http}: / / \mathrm{www}$.thefreelibrary.com/The+coming + age + of + organizational+resilience.-a020

Hosmer, L. T. (1995). Trust: The Connecting Link Between Organizational Theory and Philosophical Ethics. Academy of Management Review, 20,379-402.

Kramer, R. M., \& Tyler, T. R. (1996). Trust In Organizations: Frontiers of Theory and Research. Thousand Oaks, CA: Sage.

Longstaff, P. H., \& Yang, S. (2008). Communication Management and Trust: Their Role in Building Resilience to "Surprises" Such As Natural Disasters, Pandemic Flu, and Terrorism. Ecology and Society, 13(1), 3.

Luers, A. L., Lobell, D. B., Sklar, L. S., Addams, C. L., \& Matson, P. A. (2003). A Method for Quantifying Vulnerability, Applied to the Agricultural System of the Yaqui Valley, Mexico. Global Environmental Change, 13, 255-267. http://dx.doi.org/10.1016/S0959-3780(03)00054-2 
Matherly, M. L. (1985). A contingency model exploring the relationship of chief executive entrepreneurial: Traits and structural favorableness as predictor. Unpublished dissertation, UMI Dissertations Services.

Mayer, R. C., Davis, J. H., \& Schoorman, F. D. (1995). An Integrative Model of Organizational Trust. Academy of Management Review, 20(3), 709-734.

Mbendi, I. S. (2012). Extraction of Crude Petroleum in Nigeria-Overview. Retrieved from http://www.mbendi.com/indy/oilg/ogus/af/ng/p0005.html

McLean, A., \& Marshall, J. (1993). Intervening in Cultures. University of Bath.

Mishra, A. K. (1996). Organizational Responses to Crisis: The Centrality of Trust. In Kramer, R. M., \& Tyler, T. R. (Eds.), Trust In Organizations: Frontiers of Theory and Research (pp. 261-287). Thousand Oaks, CA: Sage. http://dx.doi.org/10.4135/9781452243610.n13

Mullins, L. J. (2005). Management and Organizational Behaviour (7th ed.). Harlow: Financial Times Pitman Publishing Imprint.

Nanus, B. (1989). The Leader's Edge: The Seven Keys to Leadership in a Turbulent World. Chicago, IL: Contemporary Books.

NNPC. (2010a). NNPC Home. Retrieved from http://www.nnpcgroup.com/Home.aspx

NNPC. (2010b). Oil Production. $\quad$ Retrieved http://www.nnpcgroup.com/NNPCBusiness/UpstreamVentures/OilProdu

NNPC. (2010c). NNPC Business: Upstream Ventures. Retrieved from http://www.nnpcgroup.com/NNPCBusiness/UpstreamVentures.aspx

Nwibere, B. M. (2007). The Interactive Relationships of Employee Commitment Types. PhD Dissertation. Faculty of Management Sciences, University of Port Harcourt, Nigeria.

Nwibere, B. M., \& Emecheta, B. C. (2012). Workplace spirituality and organizational commitment. International Journal of Business and Public Administration, 9(3), 99-125

Ouchi, W. G. (1981). Theory Z: How American Business Can Meet the Japanese Challeng. Addison-Wesley,

Posen, L. (2011). Safety and Swiss Cheese: What's the Connection? Retrieved from http://homepage.mac.com/lesposen/iblog/B80495344/C840540124/E1966059962

Samarajiva, R. (2005). Mobilizing Information and Communications Technologies for Effective Disaster Warning: Lessons from the 2004 Tsunami. New Media and Society, 7(6), 731-747. http://dx.doi.org/10.1177/1461444805058159

Schein, E. H. (2000). Organizational Culture and Leadership: A Dynamic View. Journal of Administrative Science, 15 .

Senge, P. (1990). The Fifth Discipline: The Art and Practice of the Learning Organization. New York: Doubleday.

Serrano, A. (2009). Exploring the Link Between Organizational Resilience and Crisis Management. Retrieved from http://www.continuitycentral.com/feature $0636 . \mathrm{html}$

Seville, E. (2011). Resilience: What does it mean for an organization? Retrieved from http://www.rsrc.co.nz/CAE_Bulletin.html

Shockley-Zalabak, P., Ellis, K., \& Cesaria, R. (2011b). Measuring Organizational Trust. Retrieved from http://news.iabc.com/index.php?s=56\&item=97

Shockley-Zalabak, P., Ellis, K., \& Winograd, G. (2011a). Organizational Trust: What It Means, Why it Matters. Organization Development Journal. Retrieved from http://findarticles.com/p/articles/mi_qa5427/is_200001/ai_n21464956/pg_8/?tag=mantle_skin;content

Smit, B., \& Wandel, J. (2006). Adaptation, Adaptive Capacity and Vulnerability. Global Environmental Change, 16, 282-292. http://dx.doi.org/10.1016/j.gloenvcha.2006.03.008

Spreitzer, G. M., \& Mishra, A. K. (1999). Giving Up Control Without Losing Control: Trust and Its Substitutes' Effects on Managers' Involving Employees in Decision Making. Group and Organization Management, 24(2), 155-187. http://dx.doi.org/10.1177/1059601199242003

Sutcliffe, K. (2010). Note on Organizational Resilience: Harnessing Potential In the Face of Adversity. Retrieved from http://globalens.com/featured/orgresilience/ 
Thurow, L. (1996). The Future of Capitalism. New York, NY: William Morrow and Co.

Uche, A. (2011). Marginal Fields-The Story So Far. Nigerian Oil and Gas Publication. Retrieved from http://www.nigerianoilgas.com. [29/02/2011].

Weick, K. E. (1996). Prepare Your Organization to Fight Fires. Harvard Business Review, 147-148.

Zuboff, S. (1988). In the Age of the Smart Machine, The Future of Work and World. New York, NY: Basic Books, $11-12$.

\section{Appendix}

Dimensions of Trust (Source: Mishra, 1996).

- Competence (2 items). Sample items include:

i. Our organization is effective in what we do and we are well able to survive in the market place, given the quality of our products and services and;

ii. I have confidence in the ability of the company I work for to continue being in business in order for me to achieve my personal goals".

- Openness (3 items). Sample items include:

i. Every member of the organization is well aware of events in our company. Information is shared freely;

ii. I am satisfied and happy with the level of interactions with my subordinates, peers and superiors and;

iii. there is no conducive atmosphere for freely expressing oneself. There seems to be a preferred group of people in the company".

- Reliability (2 items). Sample items include:

i. There is ample evidence of inconsistencies in the way matters are handled. Favouritism is rampant (this statement was reverse coded) and;

ii. I believe I am being fairly treated by this organization. Words are matched with action on a regular basis.

Measures of Organizational Resilience (Source: Seville, 2011).

- Vulnerability (2 items). Sample items include:

i. In the event of a crisis or disruption, our organization will not be adversely affected, and;

ii. We are strongly positioned and have put systems in place that makes us immune to the consequences of any disruptions or crisis situations.

- Adaptive Capacity (2 items). Sample items include:

i. We are capable of managing any crisis situation effectively and speedily without making significant losses, and;

ii. We are well able to recover from any disruptions to our activities and bounce back to operations even better than we were before the disruption.

Dimensions of Corporate Culture (Source: Dennison, 1990).

- Involvement index (2 items). Sample items include:

i. Most people in this company have input into decisions that affect them, and;

ii. Cooperation and collaboration across functional roles is actively encouraged in this organization.

- Consistency index (2 items). Sample items include:

i. There is a high level of agreement about the way that we do things in this company, and;

ii. Our approach to doing business in this organization is very consistent and predictable.

- Adaptability index (2 items). Sample items include:

i. Customers' comments and recommendations often lead to changes in this company, and;

ii. This organization is very responsive and changes easily.

- Mission index (2 items). Sample items include: 
i. This company has a long term purpose and direction, and;

ii. There is a shared vision of what this organization will be like in the future.

Dimensions of Organizational Structure (Source: Hage and Aiken, 1967; Hall, 1991; Matherly, 1985).

\section{- Decision making (4 items).}

This dimension assessed opportunities given to employees to involve in decision making in the organization. Sample items include:

i. Management in this organization always seeks inputs and feedbacks from employees in the process of making important decisions.

ii. Management in this organization always solicit inputs and feedbacks from employees especially on decisions that affect employees' services and wellbeing.

iii. Employees in this organization are always encouraged to be involve in decision making process, and;

iv. Employees in this organization are always given the opportunities to be involved in decision making process.

\section{- Hierarchy of authority (4 items).}

This dimension measured the degree to which employees rely on their supervisors in making their own decisions relating to the performance of tasks. Sample items include:

i. Little action can be taken until a supervisor approves a decision.

ii. A person who wants to make his or her own decision without consulting his or her supervisor will be quickly discouraged.

iii. Even small matters have to be referred to someone higher up for a final answer, "I have to ask my boss before I do almost anything, and;

iv. Any decision I make has to have my boss's approval.

\section{- Job codification (5 items).}

This dimension measured the extent to which job descriptions and work standardizations were specified. Sample items include:

i. I feel that I am my own boss in most matters.

ii. A person can make his or her own decisions without checking with anybody else.

iii. How things are done here is left up to the person doing the work.

iv. People here are allowed to do almost as they please, and;

v. Most people here make their own rules on the job.

- Rule observation (2 items).

This dimension measured the degree to which employees are supervised in conforming to the standards established in job codification. Sample items include:

i. The employees are constantly being checked on for rule violations, and;

ii. I feel as though I am constantly being watched to see if I obey all the rules.

\section{Copyrights}

Copyright for this article is retained by the author(s), with first publication rights granted to the journal.

This is an open-access article distributed under the terms and conditions of the Creative Commons Attribution license (http://creativecommons.org/licenses/by/3.0/). 